\title{
Aaron L. Berkowitz, The Improvising Mind: Cognition and Creativity in the Musical Moment. New York: Oxford University Press, 2010.
}

Although the process of musical improvisation appears to be ineffable, its mysteries have recently come to the attention of cognitive scientists. Aaron L. Berkowitz is a neuroscientist, composer and practicing pianist. In his recent book he aims, ambitiously, to explore cognition in musical improvisation. The author combines manifold methodologies (from historical examination of treatises and interviews to brain imaging) and draws on the findings from a variety of disciplines. Some readers may find the impressive number of quotations irritating, in so far as it sometimes distracts from the narrative. However, this may make it a potentially interesting source of reference to researchers new to the field of musical improvisation.

Berkowitz defines musical improvisation as "the spontaneous rule-based combination of elements to create novel sequences that are appropriate for a given moment in a given context" (p. xix). To set even more ambitious aims for his work, Berkowitz aims to go beyond music and provide insights into similarly rule-based human sets of behavior, specifically spontaneous speech and language acquisition. Importantly, readers interested in the embodied dimensions of music cognition (e.g. Leman, 2008) and musical improvisation (e.g. Iyer, 2004) may be disappointed by Berkowitz's definition, since is lacks reference to the active role of the human body in musical processing.

This relatively short book consists of nine chapters and a summarizing coda. The work is structured as two parts: Part I (Chapters 1-6) studies the knowledge base necessary for improvisation (see below) in comparison to language learning; Part II (Chapters 6 -9) explores cognition in improvised performance. In the course of this review I describe and discuss its content.

The first, introductory, chapter of the book aims to define the concepts used throughout, while defining and examining musical improvisation in terms of constraints, whether they are conventions, stylistic constraints, or performance/performer constraints. Regarding the performance constraints, Berkowitz turns to the works of Jeff Pressing (e.g. 1984), which are often referred to in the course of the book. Using Pressing and ethnomusicologist Bruno Nettl's ideas, Berkowitz points here to the existence of the knowledge base necessary for any type of improvisation. He writes: "Improvised performance in any tradition requires years of training to acquire the rules, conventions, and elements of the style that make up the knowledge base" (p. 7). The rest of this chapter is devoted to brief descriptions of issues from the psychology of learning and memory, including implicit and explicit learning and memory, and declarative and procedural memory (the "knowing that" and "the knowing how", respectively). The chapter concludes with a short comparison of music and language, this being the starting point for more detailed deliberation on this particular topic throughout the course of The Improvising Mind.

Chapter 2 is devoted to the examination of pedagogical treatises on keyboard improvisation for amateurs and music students from the late 18th to the 19th centuries. It seeks the answer to questions connected with the process of acquiring the knowledge base (or competence conceptualization) "in a manner for spontaneous use in improvised performance" (p. 17). In the following Chapter 3 Berkowitz describes the pedagogical approaches used by treatise writers to develop the improviser's "brains in the fingers" (p. 38), but does not refer to the embodied basis of music cognition. Returning to the analysis of works of Pressing, Berkowitz writes:

Once installed in memory, however, the elements of the knowledge base must be organized and refined - "enriched" in Pressing's words - if the learner is to have the kind of instant and creative access to them that is necessary for improvisation. The authors of the treatises introduced in the previous chapter converged upon four basic pedagogical strategies to accomplish these goals: transposition, variation, recombination, and the use of models that exemplify these processes in musical context. Learning a formula in various transpositions or varied realizations allows for acquaintance with the material "in intimate details, and from different perspectives", while learning how elements can be recombined, provides for "cross-linking," and "connections" between materials, to use Pressing's terminology. (p. 40)

In Chapter 3 Berkowitz focuses in detail on the abovementioned basic pedagogical strategies, interestingly drawing on concepts and research from cognitive psychology. He discusses the process of automatization as the outcome of repeated rehearsal in terms of work in neurolinguistics by Michael Paradis, and in cognitive psychology, using John Anderson's adaptive control of thought (ACT) model of learning, respectively. Berkowitz then turns to the variation strategy, this analyzed from the perspective of the 
cognitive study of oral tradition undertaken by the psychologist David Rubin (1995) and also research in the psychology of concepts (Eysenk and Keane, 2005). In this chapter, Berkowitz interestingly turns to the philosophy of the medieval Spanish thinker Ramon Lull and his idea of "ars combinatoria" (being "the method through which two or more elements can be combined", this further developed by the philosopher Gottfried Leibniz), that later led to the development of combinatorial principles in 18th century music, in the form of musical "dice games". These games "were designed by composers for amateurs, and provided a matrix of musical choices for each measure of a waltz, minuet, or other genres, with a number given to each possible option for a particular measure" (pp. 64-65). The author further analyzes recombination from developmental psychology perspectives on language and statistical learning, finally turning to the works of the music theorist Robert Gjerdingen (1988) and his research on musical "corpus" study (as analogues to the linguistic corpus studies).

In Chapter 4, Berkowitz approaches learning to improvise in the Classical style from the perspective of the learner. The author draws heavily on interviews he conducted with piano soloists who have learned to improvise in this style, including Robert Levin and Malcolm Bilson. Chapter 5, compares music and language cognition from the perspective of acquisition. Berkowitz focuses on the findings discussed in the previous chapters of the book, and extends them by reference to research and theoretical works on language learning. He aims to understand what is a knowledge base and how it is acquired. The author does this by making a comparison of the learning processes in language and music while describing the elements of their respective knowledge bases. Going further, he defines some of the terminology used in the study of language and language acquisition, while looking for analogues to such concepts in music (including phonology, morphology, syntax, semantics, and pragmatics). This chapter also contains a discussion of theories of how these knowledge bases are acquired in language and music. Among these are Chomskian nativist approaches to language acquisition and various empirical approaches (constructivism and cognitive-functional usage-based linguistics).

Chapter 6 opens Part II of the book. Berkowitz explores the musical knowledge base described in previous chapters and the way in which it can be used in performance, returning to interviews conducted with Levin and Bilson. The author returns to the concepts of implicit/procedural and explicit/declarative memory in relation to studies of amnesic patients. In Chapter 7 Berkowitz focuses on the neural correlates of phenomena described in previous chapters. Interestingly, he starts by discussing his own study (Berkowitz \& Ansari, 2008) on the neural substrates of jazz improvisation. This chapter also consists of discussion of a complementary study by Limb \& Braun (2008). The subjects of the first study were classical pianists who were asked to perform, in controlled conditions, four different tasks designed to provide variable degrees of improvisatory freedom. On the other hand, the later study: “...sought to examine improvisation in a close to its real-world form as possible, providing a more panoramic view of the full panoply of neural activity involved in improvising" (p. 143). Berkowitz concludes:

Since our study did not demonstrate activation changes in many of the frontal, temporal, or limbic regions that were shown to be active in the study of Limb and Braun, it is possible that these regions come into play only when true musical intent is present, from moment to moment and/or in the attempt to create a musical narrative over a longer timespan using one's stock of musical materials, as was the case in their experiment. (ibid.)

Chapter 8 pursues the connection between improvisation and spontaneous speech, while comparing music and language cognition from the perspective of production. Berkowitz analyses the findings of Chapters 6 and 7 in the context of theoretical and neuroscientific studies of spontaneous speech. He aims to answer the question of how the knowledge base is used in musical performance. The last chapter of the book takes the Mozart-style cadenza as a case study. Berkowitz examines it from the perspectives of pedagogical treatises on cadenzas and interviews with Robert Levin on cadenza improvisation.

To summarize, Berkowitz is interested in the knowledge base necessary for improvisation. Although the title of the book suggests the broader understanding of (music) cognition, Berkowitz's main focus is on the following questions: (1) What is this knowledge (of what elements and processes is it comprised?); (2) How do we acquire and internalize this knowledge?; (3) How is this knowledge used in performance? Thus, although his ambition to use a range of different methodologies is admirable (including the interviews that the author conducted himself), the book's title may be misleading. Among numerous references to classical books, Berkowitz limits his discussion of current empirical research to two studies that he himself conducted. Interestingly, in his article on motor sequences (Berkowitz \& Ansari, 2008) he acknowledges the literature on embodiment (including influential work on the human mirror neuron system 
(Molnar-Szakacs \& Overy, 2006)), but it is unclear why he chooses to refer solely to brain-centered manipulations in his book.

Jakub Matyja University of Huddersfield, UK

\section{References}

Berkowitz, A.L., \& Ansari, D. (2008). Generation of novel motor sequences: the neural correlates of musical improvisation. NeuroImage, Vol. 41, pp. 535-543.

Eysenk, M.W., \& Keane, M.T. (2005). Cognitive Psychology: A Student's Handbook, 5th edition. East Sussex: Psychology Press.

Gjerdingen, R. (1988). A Classic Turn of Phrase: Music and the Psychology of Convention. Philadelphia: University of Pennsylvania Press.

Iyer, V. (2004). Improvisation, temporality and musical experience. Journal of Consciousness Studies, Vol. 11, No. 3-4, pp. 159-173.

Limb, C.J., \& Braun, A.R. (2008). Neural substrates of spontaneous musical performance: An fMRI study of jazz improvisation. PLoS ONE, Vol. 3, No. 2, e1679.

Leman, M. (2008). Embodied Music Cognition and Mediation Technology. Cam., Mass.: MIT Press.

Molnar-Szakacs, I., \& Overy, K. (2006). Music and mirror neurons: From motion to 'e'motion. Social Cognitive and Affective Neuroscience, Vol. 1, No. 3, pp. 235 - 241.

Pressing, J. (1984). Cognitive processes in improvisation. In: W.R. Crozier \& A.J. Chapman (Eds.), Cognitive Processes in the Perception of Art. Amsterdam: Elsevier

Rubin, D. (1995). Memory in Oral Traditions: The Cognitive Psychology of Epic, Ballad, and Counting-out Rhymes. New York: Oxford University Press. 